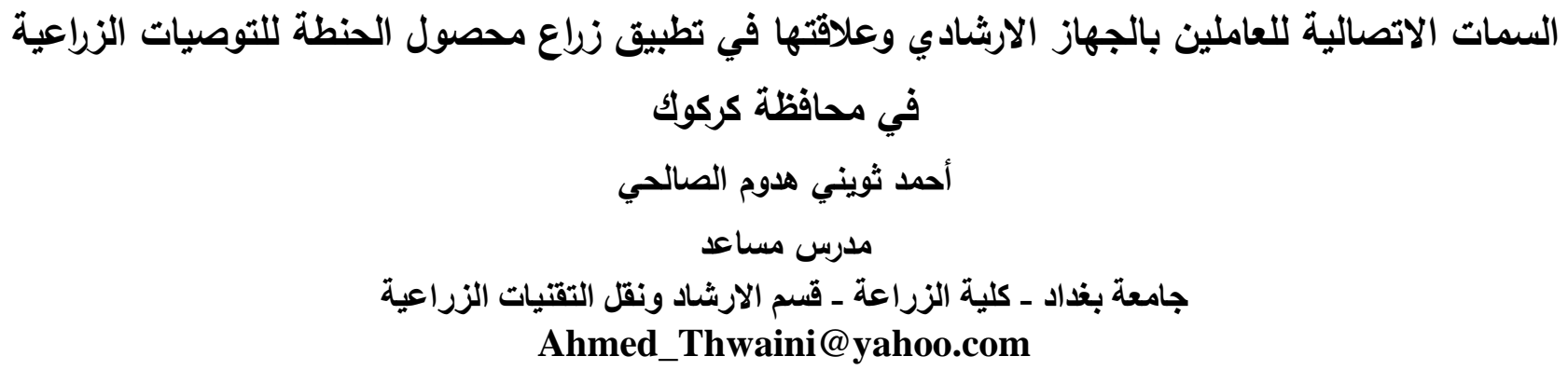

The Iraqi Journal of Agricultural Sciences - 47(1): 351-357, 2016

Al-Salhi

\title{
COMMUNICATION ACTIVITIES OF EXTENSION WORKRES AND THEIR RELATION WITH THE APPLICATION OF WHEAT GROWERS TO AGRICULTURE RECOMMENDATIONS IN THE PROVINCE OF KIRKUK
}

\author{
A. T. H. Al-Salhi
}

Ass.Lecturer

\section{ABSTRACT}

Univ of Baghdad- College of Agric - Dept. Extension and transfer of agricultural techniques

The relation between communication activities of extension agents and the applications of wheat growers to the wheat agricultural recommendations in Kirkuk, The main goal of this study was to determine it communications activities of extension agents correlated with the applications of wheat growers to wheat agricultural recommendations in the province of Kirkuk, Questionnaire was designed with to parts to achieve this study, The first part had (24) items related to communication activities (divided to four groups) and the second parts had eight item related to wheat agricultural recommendations stratified sample was used to drown the sample for 17 agriculture divisions in Kirkuk, The final sample had 150 growers from there divisions $(18 \%$ of total 832$)$, The result showed significant positive correlation (on 0.01 probability) between all communication activities and applications of wheat agricultural recommendations, in addition farmers need to improve their knowledge and skills in the area of soil management and agriculture method, All farmers need increase and give the attention and help them to build good relation whit research centers and authorities in the agriculture offices in order increase the production of wheat which is one of the best strategic crop.

KeyWord:communicationactivities,Extensionworkers,agricu Itural rec ommendations 
التعليمية عن التقنيات الجديدة (12) لذا فان غالبية الدول اخذت بالإرشاد الزراعي كمؤسسة تغيير لها حيويتها واهينها

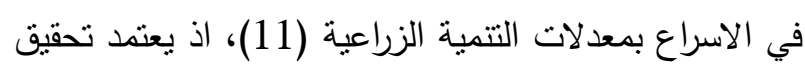
التغيير الذي يستهدفه الارشاد الزراعي في ذلك على العملية

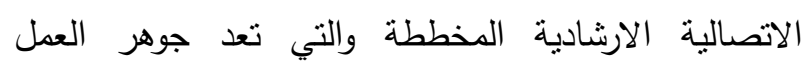
الارشادي وبدورها ترتكز على كفاءة اداء العاملين بالجهاز

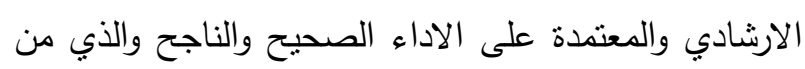
خلاله يسنطيع المرشد الزراعي اليصال الخبرات والافكار المستحدثة الى سكان الريف وبصورة تحفزهم للأخذ والاستفادة

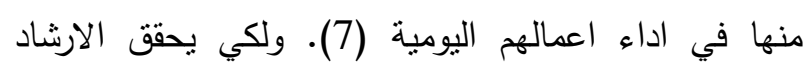
الزراعي اهدافه لابد من ان يطور وينمي امكانياته ولاسيما

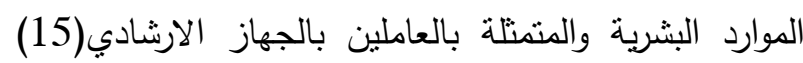
،اذ يعتمد نجاح العمل الارشادي على كفاءة وخبرة العاملين

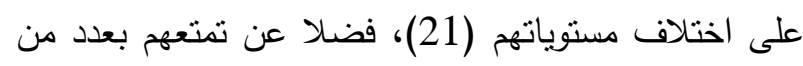

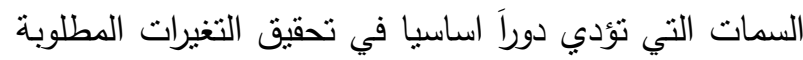
(12). وعلى وفق ذللك...... فان تحديد تلك السمات وعلاقتها بتطبيق الزراع للتوصيات اصبح موضوع اهتمام

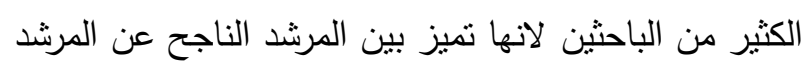
الاقل نجاحا. وبناء على ما تقدم ...... ولأهمية العاملين بالجهاز الارشادي في ايصال التقنيات الزراعية الجديدة

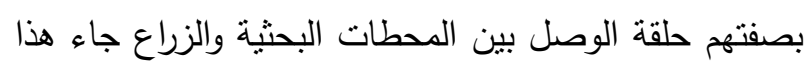
البحث ليحاول الاجابة على التساؤلات الاتية :.

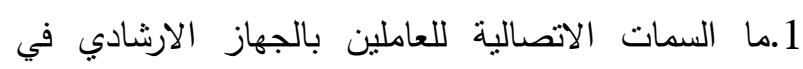
مديرية زراعة كركوك ؟ 2.مامستوى تطبيق زراع الحنطة للتوصيلات الزراعية الخاصة بمحصول الحنطة؟ 3.ما اولويات نطبيق زراع الحنطة للتوصيات الزراعية

بمحاور زراعة المحصول؟ 4.ما العلاقة الارتباطية بين السمات الاتصالية للعاملين

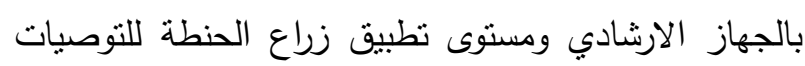
الزراعية؟ بالج

اهداف البحث

1-التعرف على السمات الاتصالية للعاملين بالجهاز الارشادي في مديرية زراعة كركوك.

2- تحديد مستوى تطبيق زراع الحنطة للتوصيات الزراعية المتعلقة بالمحصول.

\section{المقدمة}

تعد التتمية الزراعية احد القطاعات الرئيسة للتنمية الاقتصادية، التي تسعى الكثير من الدول متمنلة بوزارات

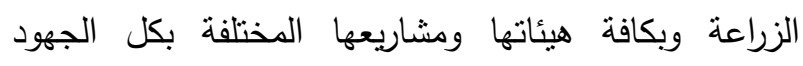
لتسريع عجلة هذه التتمية (3)، وقد شهد نهاية القرن الماضي التوجه نحو التتمية الزراعية لكثير من الدول لتصبح اكثر التره

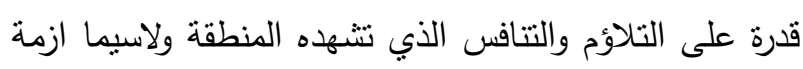
الغذاء التي تفاقدت في المرحلة الماضية (11)، فاصبح القطاع الزراعي في دول العالم ولاسيما البلدان النامية امام مواجهة تحديات تقلل من قدرته على تأمين منطلبات الغذاء داء الغاء (16) ، وعليه اثشارت اغلب التجارب الى ان معظم الدول

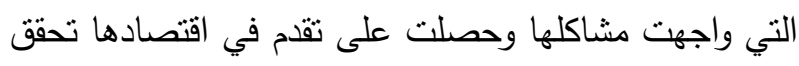
لها ذلك نتيجة التطور الذي واكب زراعتها (20)، وان الققزات التي حققتها نلك الدول في ميدان زراعتها في العقود الاخيرة من القرن الماضي جاء نتيجة نشر تقنيات زراعية عالية الانتاجية (10)، ولهذا اصبحت نتمية القطاع الزراعي وتحديث اساليبه الانتاجية ليس هدفا تسعى اليه الدول النامية

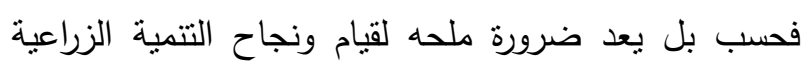

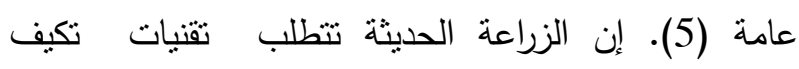
المعرفة العلمية في الزراعة وهي بذللك تعد الوسيلة الوحيدة

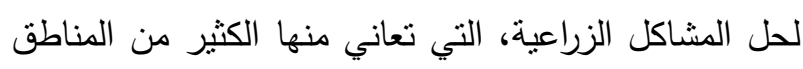

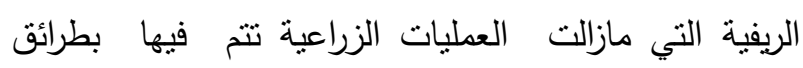

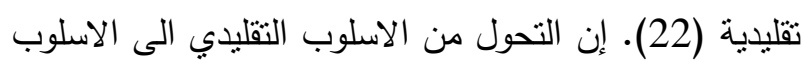

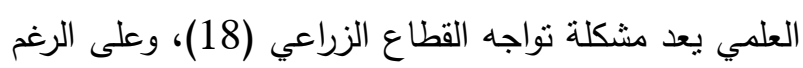

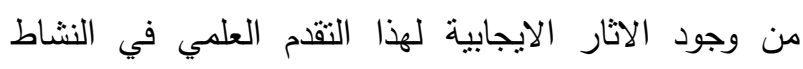

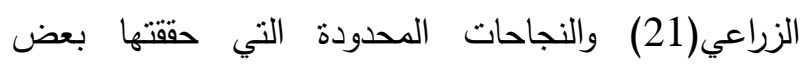
المشاريع في نشر النقنيات الزراعية في بعض المواقع (9)،

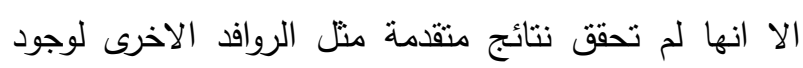
الفوارق بين نتائج البحوث الزراعية ومحطاتها وبين تطبيقها

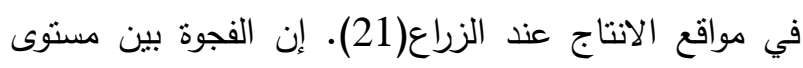
المعرفة الحالية بالتقنيات وبين ما مستخدم في المزارع الجديدة ليس من السهل تقليصها، لوجود الكثير من المعوقات التي تعترض انتشار وتطبيق هذه البحوث وتوجيهها الى سلوك لون منتج يؤدي الى الرضا الاجتماعي والاقتصادي (14)، وهذا يقع على عاتق الارشاد الزراعي بصفته احد هيئات وزارة الزراعة المسؤول عن تزويد الزراع بالمعلومات والخدمات 
موزعـة على الاقضية والنواحي ومركز مدينـة كركوك والتي

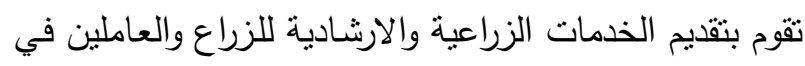
زراعة الحنطة ضمن مناطق عملهم، فضلا عن تركز أعداد

كبيرة من زراع الحنطة.

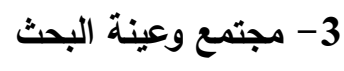

أ- مجتمع البحث

تضمن مجتمع البحث (29559) زارعا يمثلون جميع زرّاع محصول الحنطة في الشعب الزراعية التابعة لمديرية زراعة كركوك وكما في (جدول 1). جدول 1. اعداد الزراع والمساحة المزروعة في الشعب الشب الزراعية لمديرية زراعة كركوك

\begin{tabular}{|c|c|c|}
\hline 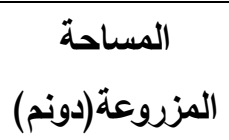 & عدد الزراع & الزراعية \\
\hline 35865 & 850 & تازة \\
\hline 84423 & 3270 & داقوق \\
\hline 14232 & 827 & ليلان \\
\hline 21118 & 366 & كركوك \\
\hline 99608 & 3650 & الرياض \\
\hline 110870 & 4094 & الحويجة \\
\hline 40853 & 2987 & العباسي \\
\hline 14112 & 3320 & الزاب \\
\hline 50523 & 1200 & التون كويري \\
\hline 42731 & 1537 & الابس \\
\hline 52744 & 1100 & سركران \\
\hline 31081 & 870 & يايجي \\
\hline 18509 & 705 & الملتقى \\
\hline 15138 & 282 & قره هنجير \\
\hline 15648 & 184 & بشير \\
\hline 60879 & 2897 & الرشّاد \\
\hline 34620 & 1420 & شوان \\
\hline 742954 & 29558 & المجموع \\
\hline
\end{tabular}

1- نم اختيار عينة عشوائية من الثعب الزراعية التابعة لمديرية زراعة كركوك وبنسبة 18\% وبواقع 3 شعب زراعية هي (شعبة زراعة كركوك، شعبة زراعة قره هنجير ، شعبة
3- التعرف على اولويات تطبيق الزراع بالتوصيات الزراعية الخاصة بمحاور محصول الحنطة. 4-تحديد العلاقة الارتباطية بين مستوى تطبيق الزراع للتوصيات الزراعية الخاصة بالمحصول و السمات الاتصالية للعاملين بالجهاز الارشادي. اهمية البحث

تؤدي الزراعة دورا مهما في تحقيق هدف التتمية الاقتصادية لعدد من البلدان النامية، اذ نتولد نسبة كبيرة من الدخل القومي عن طريق الانشطة الزراعية، فتطوير الزراعة تعد

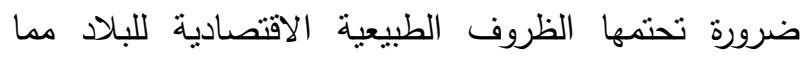
يتطلب دراسة هذا الدور وتطويره وذللك من خلال الدور الاتصالي، وبذلك تتضح اهميته من خلال العاملين بالجهاز الارشادي في عملية التغيير والذي ينتج من خلاله تطبيق الزراع للتوصيات العلمية الحديثة ، فضلا عن كونهم مصدراً لمعلومات الزراع. الفرضيات البحثية 1- امتلاك العاملين بالجهاز الارشادي السمات الاتصالية التي تمكنهم من اداء دورهم الاتصالي بشكل جيد. 2- انخفاض مستوى تطبيق زراع الحنطة للتوصيات الزراعية الخاصة بالمحصول. 3- لا توجد علاقة ارتباط معنوية بين مستوى تطبيق زرّاع محصول الحنطة للتوصيات الزراعية الخاصة بالمحصول وكل من( التعاون، حل المشكلات الزراعية، الجهود الارشادية للعاملين بالجهاز الارشادي، تلبية حاجات الزراع). المواد والطرائق 1- منهج البحث

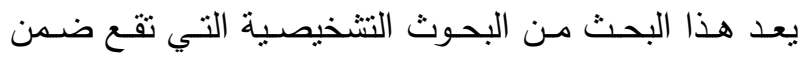
المنهج الوصفي، اذ يعد المنهج الوصفي احد اشكال التحليل والتفسير العلمي المنظم لوصف ظاهرة او مشكلة محددة عن طريـق جمـع البيانـات والمعلومـات عن تللك الظـاهرة وتحديد الوضـع الحسالي لها، ومن ثم وصفها وصفا دقيقا (13)، اذ تتمثنل هذه الظـاهرة بالسـمات الاتصـالية للعـاملين بالجهـاز

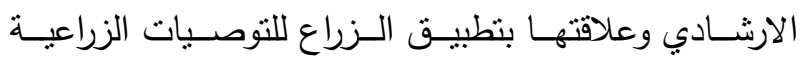
الخاصة بمحصول الحنطة في محافظة كركوك. 2- منطقة أجراء البحث :اختيرت محافظة كركوك لأجراء

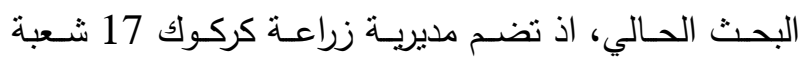


فقرة. أما القسم الثاني من الاسنمارة ، فقد احتوى مقياساً لتحديد مستوى تطبيق زراع محصول الحنطة للتوصيات

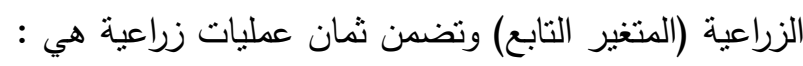
(تحضير الأرض وموعد الزراعة وطريقة الزراعة ومعدل

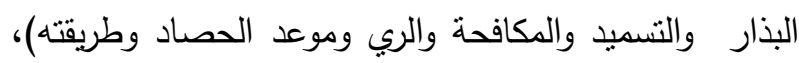
اذ تم اعطاء الزراع درجة لكل فقرة في حالة الاجابة الصحيحة وفي حالة الاجابة الخاطئة يعطى0، وبعد الحصول

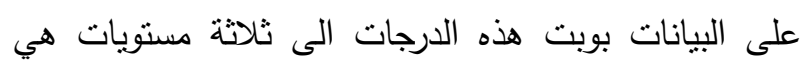
(منخفضة، متوسطة، مرتفعة) واحتسب عدد المبحوثين والنسب المئوية ومعدل التطبيق لكل مستوى. الصدق والثبات يعد صدق المقياس من اهم مظاهر المقياس الجيد ويعني قدرته على قياس ما وضع من اجله (8)، ولأجل التحقق من النماسن

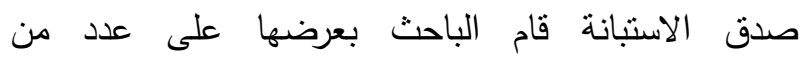
المتخصصين في مجال الارشاد الزراعي والمحاصيل الحقلية للتعرف على آرائهم وملاحظاتهم المتعلقة بنوع وسلامة وصياغة الاسئلة ومدى ملاءمتها للمبحوثين، وبعد الاخذ بملاحظاتهم اجريت بعض التعديلات على الاسئلة وبذلك تم تمبنه قياس الصدق الظاهري وصدق المحتوى للاستبيان الذي يعد احد وسائل التعرف على صدق اداة البحث ومدى تمثيل مكونات المقياس لنواحي الجوانب المقاسه (2). اجري اختبار اولي(Pre- Test) على عينة مكونة من 20 زارعاً (استبعدت من عينة البحث) ولتحديد ثبات مقياس السمات الاتصالية استخدمت طريقة الفا كرونباخ لهذه المقاييس (0.85 ، 0.80 ، 0.75 0.75 ، 0.77 ) لكل من الجهود الارشادية و تلبية حاجات

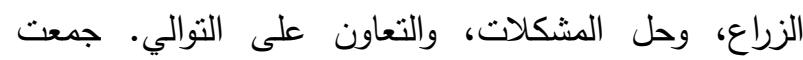
البيانات خلال شهري تشرين الاول ونتشرين الثاني من عام

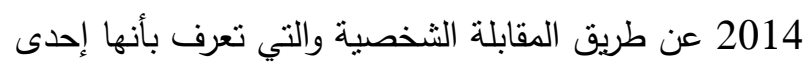
الطرق الفردية في التعليم الإرشادي، إذ تعد طريقة لجمع لنعابله المعلومات بشكل مباشر من الآخرين عن طريق الاتصال

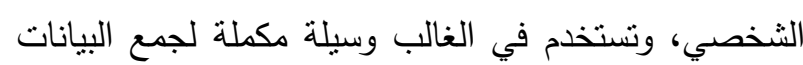

\section{الوسائل الإحصائية المستخدمة:}

بعد أجراء عملية تجميع البيانات وتفريغها وتبويبها، تم تحليل تللك البيانات باستعمال التحليل اليدوي وبرئ وبرنامج التحليل

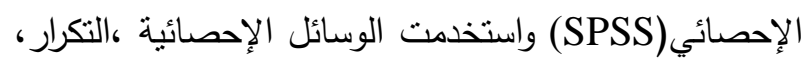

زراعة بشير) وتم استثناء اكثر من نصف الثعب الزراعية نتيجة العمليات العسكرية فيها. 2- اختيرت عينة عشوائية طبقية تتاسبية من الزراع التابعين للشعب الزراعية في مديرية زراعة كركوك والبالغ عددهم

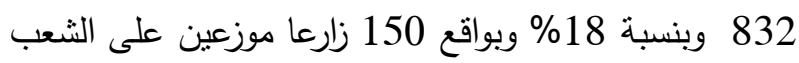
الزراعية، والمبينة إعدادهم في (جدول 2).

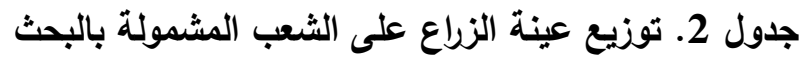

\begin{tabular}{|c|c|c|}
\hline عدد إفراد العينة & عدد الزراع & الشعبة الزراعية \\
\hline 66 & 366 & كركوك \\
\hline 51 & 282 & قره هنجير \\
\hline 33 & 184 & بشير \\
\hline 150 & 832 & المجموع \\
\hline
\end{tabular}
متغيرات البحث المتغيرات المستقلة تمنتل بالسمات الاتصالية للعاملين بالجهاز الارشادي في مديرية زراعة كركوك، وتضمنت (التعاون وحل المشكلات الزراعية الجهود الإرشادية وتلبية الحاجات) المتغير التابع تمنل بمسنوى تطبيق زراع الحنطة في مديرية زراعة كركوك

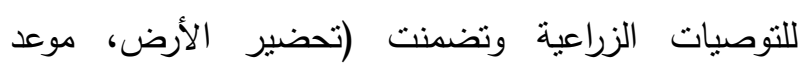
الزراعة، طريقة الزراعة، معدل البذار، التسميد، المكافحة ، الري وموعد الحصاد وطريقته). اعداد استبانة البحث وموعد لغرض تحقيق هدف البحث صممت استمارة استبانة كأداة لجمع البيانات ذات الصلة بتحقيق أهداف البحث ، إذ إذ تعد البدان الاستبانه أداة ملائمة للحصول على المعلومات والبيانات والحقائق المرتبطة بواقع معين، وتقدم على شكل مجموعة من

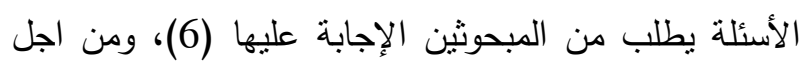
الحصول على البيانات اللازمة حول متغيرات البحث تكونت الإنه الاستمارة من جزئين وكالاتي:احتوى الجزء الأول منها على اربعة مقاييس للسمات التهات الاتصالية (المتغيرات المستقلة) تضمن كل منها 6 فقرات، وبمجموع 24 فقرة لجميع المقاييس، ووضع مقياس ثلاثي متدرج يتكون من ( قليلة، متوسطة، كثيرة)، لقياس مدى توفر

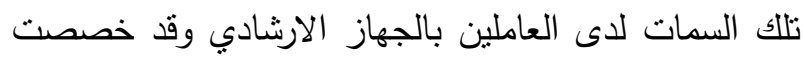
قيم لهذا المقياس وكالاتي (1,2,3) وعلى النوالي امام كل 
اهتمام العاملين بالجهاز الارشادي لأهمية العلاقات التعاونية بينهم وبين الجهات الأخرى ذات العلاقة. الهرف الثاني: تحديد مستوى تطبيق الزراع للتوصيات الزراعية الخاصة بمحصول الحنطة.

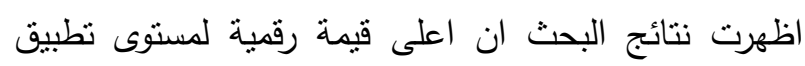
زراع محصول الحنطة للتوصيات الزراعية بلغت 17 درجة وادنى قيمة رقمية هي 6 درجة على مقياس مستوى نطبيق بلغت درجاته بين (0-20) درجة وبمتوسط مقداره (12.48) درجة وبانحراف معياري مقداره (2.31) درجة، وقد تم توزيع المبحوثين على وفق درجات نطبيقهر الى ثلاثة مستويات (منخفض، متوسط، مرتفع) وكما في (جدول 4). جدول4. توزيع المبحوثين وفقاً لمستوى تطبيقهم للتوصيات الزراعية الخاصة بمحصول الحنطة.

\begin{tabular}{|c|c|c|c|c|c|}
\hline الملاحظات & مستوىى & $\%$ & العدد & درنتوى & التطبيق \\
\hline $\mathrm{SD}=2.3$ & 8.50 & 13 & 20 & $9-6$ & ضنذف \\
\hline$X=12.48$ & 11.91 & 52 & 78 & $13-10$ & متوسط \\
\hline$N=150$ & 14.88 & 35 & 52 & $17-14$ & مرتفع \\
\hline & & 100 & 150 & \multicolumn{2}{|c|}{ المجموع } \\
\hline
\end{tabular}

يتضح من الجدول اعلاه، ان اكثر من نصف المبحوثين كان مستوى تطبيقهم للتوصيات الزراعية الخاصة بمحصول الحنطة يقع ضمن الفئة المنوسطة وبنسبة (52\%) وبمتوسط مقداره (11.91) ،اي ان مستوى تطبيق المبحوثين للتوصيات الزراعية يوصف بالمتوسط الذي يميل للارتفاع، وقد يعود

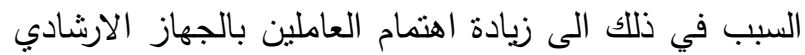
بنقل اخر التوصيات الزراعية الخاصة بمحصول الحنطة، فضلا عن تمسك المبحوثين بالبحث عن كل ما هو جديد في زراعة محصول الحنطة. الههف الثالث التعرف على اولويات تطبيق الزراع الخاصة بمحاور زراعة

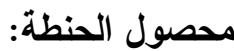
تم تحديد اولويات تطبيق زراع محصول الحنطة لمحاور

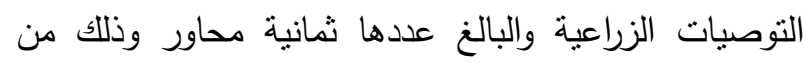
خلال النسب المئوية للمطبقين للك لمحور وكما في (جدول
النسبة المئوية، المتوسط الحسابي (1)، الانحراف المعياري

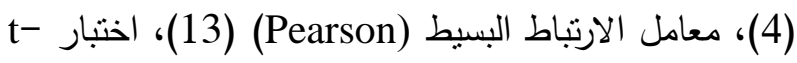
test النتائج والمناقشة الهدف الاول:- التعرف على اراء المبحوثين على السمات الاتصالية للعاملين بالجهاز الارشادي.

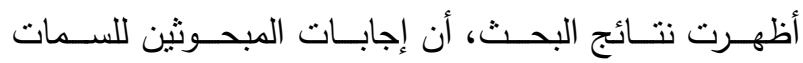
الاتصالية والبالغ عددها 4 سمات، حصلت على وسط مرجح إنح يقــع بـين (2.02-212) درجــة ، ووزن مئسوي يقــع بــين

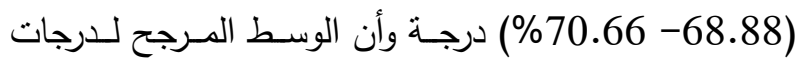
موافقة المبحوثين على أي من السمات الاتصـالية هو أعلى ورنى

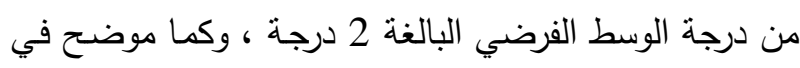

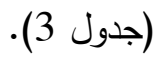
جدول 3. توزيع المبحوثين وفقاً لأرائهم على السمات الاتية للعاملين بالجهاز الاششادي.

\begin{tabular}{|c|c|c|c|c|}
\hline المتوسن & الالمتوسط & السمات الاتصالية & تسلبل & تسلسل \\
\hline 70.66 & 2.12 & الجهود الارشادية & 1 & 3 \\
\hline 69.66 & 2.09 & تلبية الحاجات & 2 & 4 \\
\hline 69.49 & 2.08 & حل المشكلات & 3 & 2 \\
\hline 68.88 & 2.02 & التعاون & 4 & 1 \\
\hline
\end{tabular}
يتبين من الجدول اعـلاه، أن جميع السمات الاتصـالية التي

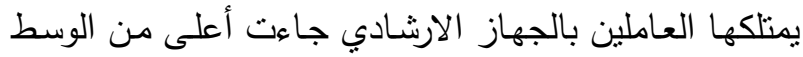
الفرضسي، وعلى الـرغم مسن ذلـك جـاءت الجهـود الارشــادية

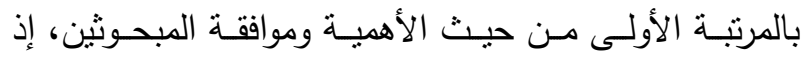
حققت وسطاً مرجحاً قدره (2.12) درجة، وبوزن مئوي قدره (70.66\%) درجة، وهو أعلى من الأوساط المرجحة للسمات

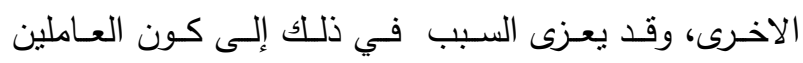
بالجهاز الإرشادي يرغبون في البحث عن حلول تلائم الواقع بعزي

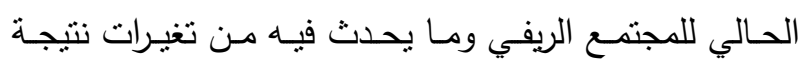

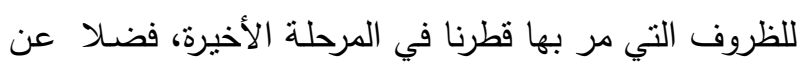

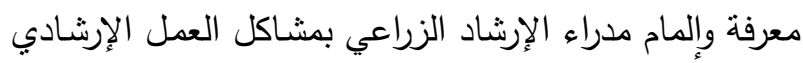

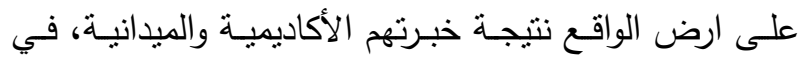

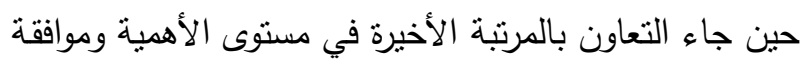

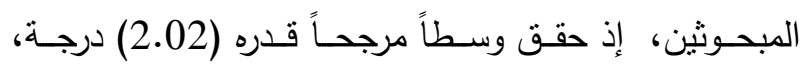
وبوزن مئوي قدره (68.88\%) درجة، وهو اقل من الأوساط المرجحة للمحاور الأخرى، وقد يعود السبب في ذلك الى قلة 
يستتتج من الجدول اعلاه، ان اعلى مستوى تطبيق جاء عند

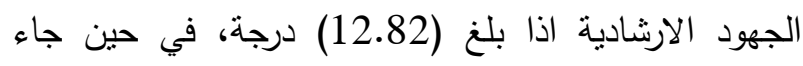
التعاون كأدنى مستوى تطبيق اذ بلغ (12.37) درجة، ولمعرفة فيما اذا كانت هناك علاقة ارتباطية بين مستوى زراع بطئع الحنطة والسمات الاتصالية، استخدم معامل الارتباط البسيط

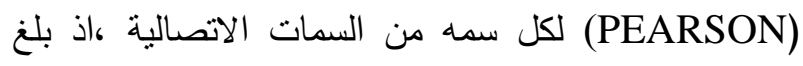
(0.79) وعلى مستوى 0.01 لسمة التعاون وهذا يدل على وجود علاقة موجبة بين المتغيرين. في حين بلغ معامل الارتباط البسيط (PEARSON) لسمه حل عله المشكلات الزراعية المتعلقة بمحصول الحنطة (0.40) وعلى مستوى الاربط معنوية 0.01 وهذا يدل على وجود علاقة موجبة بين المتغيرين. بينما بلغ معامل الارتباط البسيط (PEARSON) لسمه الجهود الارشادية (0.61) وعلى مسنوى معنوية لإنية 0.01 لذلك ترفض فرضية العدم وتقبل الفرضية البديلة.اما سمه تلبية الحاجات فقد بلغ معامل الارتباط البسيط (0.65) على مستوى معنوية 0.01 وهذا يدل على وجود علاقة موجبة بين المتغيرين. نستتتج مما سبق بان السمات

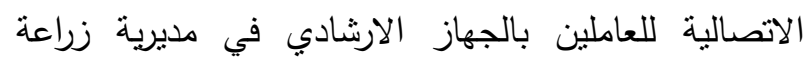
كركوك تشكل حالة تفاعل، اذ يرتبط كل منها بمستوى تطبيق زراعة الحنطة للتوصيات الزراعية، وان مستوى تطبيق زراع محصول الحنطة كان متوسطا، كما ان زراع محصول الحنطة بحاجة الى زيادة معارفهم ومهاراتهم في محور تحضير الارض وطريقة الزراعة لحصولهم على المرنبة الاخيرة، وتواصلا مع ما خلص إليه البحث الحالي من

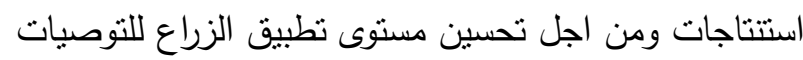
الزراعية يوصي الباحث بضرورة الاهنمام بمحصول الحنطة كونه من المحاصيل الاستراتيجية وذلك بالتعاون مع الجهات البحنثة وتوثيق العلاقة بينهم وبين الجهات ذات العلاقة، والاستمرار بدعم البرامج التدريبة لتتمية ونطوير معارف ومهارات مزارعي الحنطة وذلك من خلال تكثيف الانشطة الارشادية من قبل وزارة الزراعة والمتمنلة بدائرة الارشاد مناد

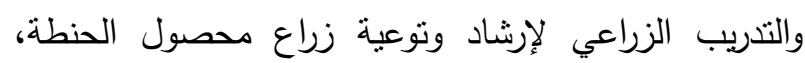

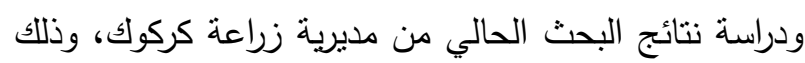
للاستفادة منها في الوقوف على المشاكل التي تعترضهم اثثاء تطبيقهم للتقنيات الجديدة.
جدول5. اولويات تطبيق الزراع للتوصيات الزراعية الخاصة بمحاور زراعة محصول الحنطة

\begin{tabular}{|c|c|c|c|}
\hline للنبطة المئوية & العدد & المحور & الالهبلة حسبل \\
\hline 100 & 150 & موعد الحصاد & 1 \\
\hline 90.66 & 136 & موعد الزراعة & 2 \\
\hline 89.33 & 134 & التسميد & 3 \\
\hline 84 & 126 & المكافحة & 4 \\
\hline 80 & 120 & معدل البذار & 5 \\
\hline 77.33 & 116 & الري & 6 \\
\hline 76 & 114 & تحضير الارض & 7 \\
\hline 26.66 & 40 & طريقة الزراعة & 8 \\
\hline
\end{tabular}

يتضح من الجدول اعلاه ،ان محور موعود الحصاد وطريقته جاء بالمرنبة الاولى من حيث مستوى الاهمية وتطبيق الزراع للتوصيات الزراعية اذا حصل على نسبة مئوية قدرها (100\%)، ويعود السبب في ذلك على علم كافه المبحوثنين بالتوصيات الزراعية الخاصة بالموعد المحدد والاليه المستخدمة.في حين جاءت بالمرتبة الاخيرة من حيث مستوى بالتوصيات

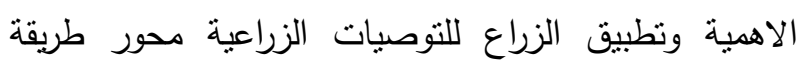

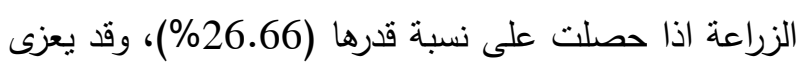
السبب في ذلك كون غالبية المبحوثين يستخدمون طريقة النثر

في الزراعة وقلة منهم يستخدمون طريقة البذار الالية.

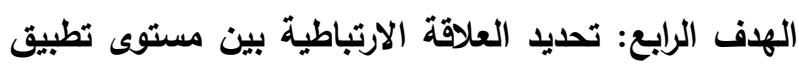
زلراع الحنطة للتوصيات الزراعية والسمات الاتصالية للعاملين بالجهاز الارشادي.

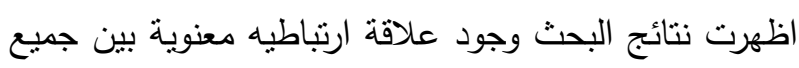
متغيرات البحث ومسنوى التطبيق وعلى مستوى معنوية (0.01) وكما موضح في (جدول 6).

جدول رقم 6. العلاقة الارتباطية بين تطبيق الزياع للتوصيات الزراعية الخاصة بالمحصول و السمات الاتصالية للعاملين بالجهاز الارشادي.

\begin{tabular}{|c|c|c|c|c|}
\hline الجدولية & $\begin{array}{c}\mathbf{T} \\
\text { المحسوبة }\end{array}$ & الارتباط & مستوى معدى & الاتصالية \\
\hline \multirow{4}{*}{$\begin{array}{l}0.01=2.33 \\
0.05=1.64\end{array}$} & 15.5 & $0.79^{* *}$ & 12.37 & التعاون \\
\hline & 5.30 & $0.40^{* * *}$ & 12.50 & حل المشكلات \\
\hline & 9.42 & $0.61^{* *}$ & 12.82 & الا شادهودة \\
\hline & 10.47 & $0.65^{* *}$ & 12.49 & تلبية الحاجات \\
\hline
\end{tabular}




\section{REFERENCES}

1. Abdel-Hafiz, A.M, Mustafa. H .2000.

Methods of Scientific Research and Statistical Analysis in the Educational, Psychological and Sports Areas of Cairo, book publishing center, pp.450.

2.Al-Ansari, M. B. 2000. The Personal Measure, modern books, Egypt,pp.97.

3. Aldharas, A.N. 2009. Study Some of The Factors Influencing the Adoption of Agricultural Technologies to Crop Wheat and Sources of Information, M.Sc Thesis, Coll. of Agric, Univ. of Sanaa, Yemen pp.12.

4. Al-Jubouri, S. H. 1999. Applied Statistics, p1, leaflets and the Ministry of Higher Education and Scientific Research, Baghdad, pp.64.

5. Al-Khafaji, A. M , and Faisal. M. S. 1998, Agricultural Extension and ways of development, leaflets Omar Al-Mukhtar Univ. Libya, pp. 13

6. Al-magrbee, M. K. 2002. Methods of Scientific Research, the House of Culture for Publishing and Distribution, Amman, Jordan.pp.25.

7. Al-Obeidi, A. F .2008. Communication Skills those Working in the Agricultural Extension the Province of Nineveh and Its Relationship With Some Personal and Functional Characteristics, M.Sc Thesis, coll. of Agric, Univ. of Mosul, pp.83.

8. Al-Sarraf, Q. A. 2002. Measurement and Evaluation in Education, National Library of modern publishing, Alexandria,pp.199.

9. Altaie, H. K .2005. Good Management For The Transfer of Agricultural Technology, Journal of Iraqi agriculture, 3th, pp.3

10. Altaie,H.K.2004. The Productivity Gap in

The Transfer of Agricultural Technology Process, the Iraqi Journal of Agriculture, the second issue,pp. 3

11. Arab Organization for Agricultural Development, 1996, the National Seminar on strengthening the role of agricultural extension in sustainable development, Khartoum, Sudan,pp. 25
12. Arab Organization for Agricultural Development, 1997, the role of agricultural extension in the transfer of research results to farmers and its impact on development, Khartoum, Sudan, pp15.

13. Atabi, J. M .1991. The Methods of Social Research, the publication of the National Library, Coll. of Agric and Forestry, Univ. of Mosul,pp87.

14. Edgar L.B, and Jones.J.2002. Developing Programs in Adult Education, $2^{\text {th }}$ ed , Waveland Press, inc, printed and bound in the USA, pp65.

15. Fltzpatrick ,J. L., and Sanders, J. R., 2004, Program Evaluation, $3^{\text {th }}$ ed, printed and bound in the USA, pp15.

16. Hussein, R. J, 2009, lectures in the Subject of Methods of Transportation of Agricultural Techniques, body of technical education, technical college Musayyib, pp.3.

17. Idris, Th. A .2001, The Entrance to Talk in Public Administration, p 1, University House Publishing, Cairo, pp.17.

18. Knowles, M.S , and Richard, A.S, The Adult Learner, 2011, seventh edition , printed and bound in the USA, pp58

19. Murad, S. A. 2002. Tests and Standards in The Psychological and Educational Science and Preparation steps, Dar modern books for printing and publishing, Kuwait,pp.102.

20.Rogers ,E. M., 2003, Diffusion of Innovation, $5^{\text {th }}$ ed, printed in the New York,Ny, USA, P 25.

21. Sheikh, J. D.1999. Study Analysis of Some of The Personal, social and economic factors on the level of performance of agricultural extension workers for their guidance, Ph.D. coll. of Agric, Univ. Cairo, Egypt, pp.3.

22. Watts, L. H.,1984, The organization setting for agricultural extensions, Agricultural Extension A reference manual, Roma, $2^{\text {nd }}$. Ed.,pp.20 